and these gave fairly good results under experimental conditions.

The obvious explanation would appear to be that these animals had been affected by the extremely hot weather, which was unusual for the locality. If this is so, then we have an interesting example of a species being subjected, but at very considerable intervals only, to highly unfavourable conditions of temperature. This presumably would result in a high degree of selection for temperature resistance, but the length of the intervals between the times of stress would allow the selection to be largely negatived by crossing and recombination.

It would be of considerable interest to know whether similar effects of the abnormally hot weather on littoral animals have been noticed elsewhere this season.

King's College,

Strand, W.C.2.

'J. Exp. Zool., 58, 495-523.

\section{Selenium Dehydrogenation of Sitosterol}

$\mathrm{WE}$ have reported ${ }^{1}$ that the selenium dehydrogenation of cholesterol $\mathrm{C}_{27} \mathrm{H}_{46} \mathrm{O}$ and ergosterol $\mathrm{C}_{28} \mathrm{H}_{44} \mathrm{O}$ gives two different hydrocarbons, $\mathrm{C}_{25} \mathrm{H}_{24}$, m.p. $225^{\circ}$, and $\mathrm{C}_{26} \mathrm{H}_{26}$, m.p. $214^{\circ}$, respectively, while Diels and Karstens ${ }^{2}$ claimed the formation of only one product, $\mathrm{C}_{25} \mathrm{H}_{24}$, m.p. $220^{\circ}$, from both sterols. Diels now suggests ${ }^{3}$, without new experimental work, that our hydrocarbons might be impure and insists on their identity. Cook and Hewett also think the diversity of the two hydrocarbons improbable and assign to them the formula $\mathrm{C}_{25} \mathrm{H}_{22}$ proposed by Rosenheim and Kings ${ }^{5}$.

$W_{\Theta}$ have found in the meantime that the X-ray spectra of our two hydrocarbons are distinctly different and that there is another argument for their diversity. If the two hydrocarbons were identical, sitosterol $\mathrm{C}_{29} \mathrm{H}_{50} \mathrm{O}$ would furnish by the selenium dehydrogenation the same hydrocarbon. We obtained, however, by the latter reaction a new hydrocarbon melting at $202^{\circ}-203^{\circ}$ (found $\mathrm{C} 91.9$, $\mathrm{H} 8.0$; calculated for $\mathrm{C}_{27} \mathrm{H}_{28}, \mathrm{C} 92 \cdot 0, \mathrm{H} 8 \cdot 0$ ) ; melting point of the compound with dinitro-anthrachinone, $246^{\circ}-247^{\circ}$. We do not believe, therefore, that any doubt can exist about the correctness of our formulation of the described dehydrogenation products. The detailed results will appear in the Acta Helvetica.
I. RUZickA.
M. W. Goldberg.
G. Thomann.
E. BRANDENBERGER.

Technical High School, Zurich.

Sept. 22.

'Acta Helv., 16, 812; 1933

2 Annalen, 478, $135 ; 1930$

B Ber., 68, 1124; 1933.

SChem and Ind $52,301933$.

\section{Addition of Hydrogen Bromide to Olefinic Acids}

IN a recent study ${ }^{1}$ of the action of hydrogen bromide on a number of simple $\Delta^{2}$ - and $\Delta^{3}$-olefinic acids, it was shown that the direction of addition was profoundly influenced by the nature of the solvent and it was suggested that in hydrocarbon solvents the carboxyl group controlled the orientation of addition whereas in acetic acid or in the absence of solvent the double bond behaved independently of this group. After the completion of this work, Kharasch ${ }^{2}$ published his remarkable discovery that the direction of addition of hydrogen bromide to allyl and vinyl bromides was controlled mainly by the peroxide content of the material. In view of this it was considered desirable to determine to what extent the presence of peroxides could influence addition to the simple olefinic acids. Experiments for this purpose are in hand.

J. C. Smith ${ }^{3}$ has now reported that the direction of the addition of hydrogen bromide to undecylenic acid in ligroin, which normally is such as to yield the terminal bromo-acid, is substantially reversed in the presence of hydrogen, or diphenylamine. In view of this interesting extension of Kharasch's work we think it desirable to state that experiments with allyl acetic acid indicate that the peroxide effect is here of secondary importance. Addition to the acid in hexane normally yields pure- $\delta$-bromo-valeric acid and we have been unable to reverse this in the presence of hydrogen, diphenylamine or hydroquinone. Moreover, both the freshly prepared acid and a very stale sample which yielded a strong peroxide reaction gave $\gamma$-bromo-valeric acid in the absence of solvent. A reversal of the addition to the acid in the absence of solvent can, however, be induced by the addition of benzoyl peroxide, which leads to the production of $\delta$-bromo-acid. In this respect allyl acetic acid recalls the behaviour of propylene ${ }^{2}$.

It thus appears that the importance of the peroxide effect varies with different unsaturated acids and that it cannot account for the influence of the solvent on the addition of hydrogen bromide to allyl acetic acid.

Imperial College of Science,

R. P. Linstead

H. N. RYDon.

South Kensington. Sept. 30.

${ }^{1}$ Boorman, Linstead and Rydon, J. Chem. Soc., 568 ; 1933. 2 Kharasch and Mayo, $J$. Amer. Chem. Soc., 55, 2468; 1933. Kharasch McNab and Mayo, ibid., 2521, 2531

${ }^{3}$ J. C. Smith, NATURE, 132, 447, Sept. 16, 1933.

\section{The "Leeds Portrait" of Joseph Priestley}

IN a communication in Naxure of June 17, p. 876 , by one of us (W. C. W.), a reproduction of the earliest known portrait of Joseph Priestley appeared for the first time and with it a request for information regarding the present whereabouts of the original. This appeal failed to produce any replies, but extensive private inquiries in which we were jointly engaged have recently proved successful. We are unable to divulge the address of the owner of the portrait, but we have permission to state that it is in a private collection of family portraits in the possession of a grand-daughter of Mrs. Bilbrough (née Ellen Priestley) now living in Cheshire.

The owner has agreed to confidential notification being made to the secretaries of the Royal Society and to the Trustees of the National Portrait Gallery of the fact that the picture is in her possession.

Some details of its history, too long to be given here, will be published elsewhere.

Douglas McKre.

W. Cameron Walker.

Department of the History of Science,

University College, London. 